ИНФОРМАТИВНОСТЬ НАТРИЙУРЕТИЧЕСКОГО ПЕПТИДА В-ТИПА У КАРДИОХИРУРГИЧЕСКИХ БОЛЬНЫХ С ГИПЕРКРЕАТИНИНЕМИЕЙ

\author{
М. Г. Буржунова ${ }^{1}$ О. Г. Гусева ${ }^{1}$ В. Ю. Рыбаков ${ }^{2}$ Л. А. Кричевский ${ }^{1,2}$, И. А. Козлов \\ ${ }^{1}$ НИИ общей реаниматологии им. В.А.Неговского РАМН, Москва \\ ${ }^{2}$ Городская клиническая больница № 15 им. О. М. Филатова Департамента здравоохранения г. Москвы
}

\title{
The Informative Value of N-Terminal Pro-type B Natriuretic Peptide in Cardiac Surgical Patients with Hypercreatininemia
}

\author{
M. G. Burzhunova1, O. G. Guseva², V. Yu. Rybakov², L. A. Krichevsky ${ }^{1,2}$, I. A. Kozlov ${ }^{1}$ \\ ${ }^{1}$ V. A. Negovsky Research Institute of General Reanimatology, Russian Academy of Medical Sciences, Moscow \\ ${ }^{2}$ O. M. Filatov City Clinical Hospital Fifteen, Moscow Department of Healthcare
}

\begin{abstract}
Цель исследования - изучить информативность резкого повышения дооперационного уровня неактивной части предшественника натрийуретическиого пептида B-типа (NT-proBNP) в крови у кардиохирургических больных с гиперкреатининемией. Материал и методы. Обследовали 21 больного с дооперационным уровнем NT-proBNP 1000 пг/мл и более, которым выполняли реваскуляризацию миокарда в условиях искусственного кровообращения. Больных разделили на группы с нормальным (до 120 мкмоль/л) содержанием креатинина (1-я группа; $n=11$ ) в крови и с гиперкреатининемией $(2-я$ группа; $n=10)$. Данные о показателях кровообращения обрабатывали после кожного разреза и в конце операции. Анализировали клинические особенности периоперационного периода. Результаты. Креатининемия в 1-й группе составляла $103 \pm 3,3$, во 2 -й $-183 \pm 12,9$ мкмоль/л $(p<0,05)$; уровень NT-proBNP $-1397 \pm 139$ и $1908 \pm 170$ пг/мл $(p<0,05)$. Прогнозируемая по шкале EuroSCORE летальность достигала 9,8 $\pm 1,6$ и 9,1 $\pm 1,7 \%(p>0,05)$. Интраоперационные показатели кровообращения не имели межгрупповых отличий. Интенсивность симпатомиметической терапии после искусственного кровообращения у больных выделенных групп была одинаковой, также не различались $(p>0,05)$ частота использования внутриаортальной баллонной контрпульсации $(18,2$ и 10,0\%), длительность

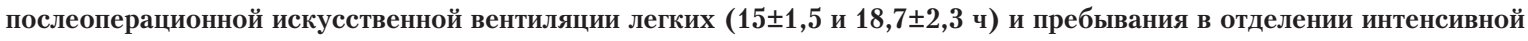
терапии у выживших больных $(1,8 \pm 0,5$ и $2,0 \pm 0,7$ сут), а также госпитальная летальность $(23,7$ и $20,0 \%)$, которая в обеих группах оказалась существенно выше прогнозируемой летальности по шкале EuroSCORE. Регрессионный анализ показал, что по всей выборке оперированных больных уровень NT-proBNP оказался более значимым предиктором $(p=0,012)$ госпитальной летальности, чем показатель, рассчитанный по шкале EuroSCORE $(p=0,04)$. Аналогичная закономерность была характерна для больных без гиперкреатининемии, у которых и NT-proBNP $(p=0,012)$, и шкала EuroSCORE $(p=0,026)$. У больных с гиперкреатининемией показатель «предполагаемая летальность по EuroSCORE» полностью потерял значимость $(p=0,61)$ в прогнозе реальной летальности. Уровень NT-proBNP в этой группе проявлял тенденцию $(p=0,06)$ к предикторному влиянию. Заключение. Содержание NT-proBNP в крови 1000 пг/мл и выше сохраняет свою значимость, как фактор высокого операционного риска, при реваскуляризации миокарда в условиях ИК у больных с гиперкреатининемией в пределах 140-270 мкмоль/л. Ключевые слова: натрийуретические пептиды Втипа, NT-proBNP, реваскуляризация миокарда, искусственное кровообращение, гиперкреатининемия.
\end{abstract}

Objective: to study the informative value of a dramatic increase in the preoperative blood level of the inactive moiety of the precursor of N-terminal pro-type B natriuretic peptide (NT-proBNP) in cardiac surgical patients with hypercreatininemia. Subjects and materials. Twenty-one patients with a preoperative NT-proBNP level of $1000 \mathrm{pg} / \mathrm{ml}$ or more, who underwent myocardial revascularization under extracorporeal circulation (ECC), were examined. The patients were divided into groups with normal (up to $120 \mu \mathrm{mol} / 1$ ) (Group 1; $n=11$ ) and elevated (Group 2; $n=10$ ) creatinine concentrations. The values of circulation were processed after skin incision and at the end of surgery. The clinical features of a perioperative period were analyzed. Results. Creatininemia was $103 \pm 3.3$ and $183 \pm 12.9 \mu \mathrm{mol} / 1$ in Groups 1 and 2 , respectively $(p<0.05)$; NT-proBNP was $1397 \pm 139$ and $1908 \pm 170 \mathrm{pg} / \mathrm{ml}(p<0.05)$. EuroSCORE-predicted mortality ran to $9.8 \pm 1.6$ and $9.1 \pm 1.7 \%(p>0.05)$. There were no intergroup differences in intraoperative circulatory parameters. The intensity of sympatomimetic therapy after ECC was equal in the identified patient groups and there were either no differences $(p>0.05)$ in the frequency of intra-aortic balloon counterpulsation $(18.2$ and $10.0 \%)$, the length of mechanical ventilation (15 \pm 1.5 and $18.7 \pm 2.3$ hours) and intensive care unit stay $(1.8 \pm 0.5$ and $2.0 \pm 0.7$ days $)$ in survivors, and inpatient mortality (23.7 and $20.0 \%$ ) that proved to be substantially higher than the EuroSCORE-predicted one. Regression analysis showed that in the entire group of operated patients, the level of NT-proBNP turned out to be a more signifi-

Адрес для корреспонденции (Correspondence to):

Буржунова Мадина Гаруновна

E-mail: burzhunova@gmail.com cant predictor of inpatient mortality $(p=0.012)$ than EuroSCORE-predicted one $(p=0.04)$. The similar regularity was characteristic for patients with hypercreatininemia. In the patients with hypercholesterolemia, the EuroSCORE-predicted mortality completely lost its significance $(p=0.61)$ in predicting actual mortality rates. In 


\section{Маркеры критических состояний}

this group, NT-proBNP showed a predicting trend. Conclusion. The blood NT-proBNP concentration of $1000 \mathrm{pg} / \mathrm{ml} \mathrm{or}$ more preserves its significance as a high operative risk factor in the presence of myocardial revascularization under ECC in patients with the blood creatinine level of 140-270 $\mu \mathrm{mol} / 1$. Key words: $\mathrm{N}$-terminal pro-type B natriuretic peptide (NTproBNP), myocardial revascularization, extracorporeal circulation, hypercreatininemia.

Предикторная значимость уровня в крови неактивной части предшественника натрийуретическиого пептида B-типа (NT-proBNP) у кардиохирургических больных в настоящее время не вызывает сомнений [1-4]. Однако информативность повышения NT-proBNP при хронической недостаточности кровообращения, сопровождающейся или сочетающейся с гиперкреатининемией, остается предметом дискуссии, поскольку нарушение функции почек может быть причиной накопления в крови биологически инертного полипептида. Установлена тесная взаимосвязь между снижением клиренса креатинина и повышением концентрации биомаркера [5, 6]. Умеренная гиперкреатининемия является нередким клиническим признаком у кардиохирургических больных высокого операционного риска [7], для которых характерен повышенный уровень NT-proBNP [4].

Отдельные исследователи высказывают мнение о снижении информативности NT-proBNP у кардиологических больных с гиперкреатининемией [8]. Другие, напротив, указывают на высокую предикторную значимость повышения уровня биомаркера даже на фоне терминальной почечной недостаточности [9].

Изложенное определило цель настоящего исследования - изучить информативность резкого повышения дооперационного уровня NT-proBNP у кардиохирургических больных с гиперкретининемией.

\section{Материал и методы}

В исследование включали кардиохирургических больных с дооперационным уровнем NT-proBNP 1000 пг/мл и более. Обследовали 21 больного (19 мужчин и 2 женщины) ишемической болезнью сердца (ИБС) в возрасте 49-72 $(63,7 \pm 1,7)$ лет, которым выполняли реваскуляризацию миокарда в условиях искусственного кровообращения (ИК). Постинфарктные изменения миокарда регистрировали в 95\% наблюдений, дооперационная фракция изгнания левого желудочка (ФИЛЖ) составила $16-45(31,3 \pm 2,4) \%$, тяжесть состояния соответствовала III-IV $(3,3 \pm 0,1)$ функциональному

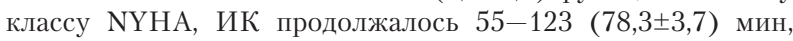
ишемия миокарда (ИМ) $-24-88(40,4 \pm 2,2)$ мин. Предполагаемый риск летальности, рассчитанный по шкале EuroSCORE, составил $1,4-19,7(9,7 \pm 1,6) \%$.

Больных разделили на группы с нормальным (до 120 мкмоль/л) содержанием креатинина (1-я группа; $n=11)$ в крови и с гиперкреатининемией (2-я группа; $n=10)$. Группы не отличались $(p>0,05)$ : по возрасту $-65,3 \pm 2,4$ и $62,0 \pm 2,2$ лет; дооперационной ФИЛЖ - 28,3 $\pm 1,3$ и $31,1 \pm 2,6 \%$; функциональному классу NYHA - 3,4 $\pm 0,1$ и $3,2 \pm 0,1$; длительности ИК $-82 \pm 5,6$ и $72,4 \pm 3,1$ мин; продолжительности ИМ $-42,7 \pm 5,5$ и $38,2 \pm 2,5$ мин

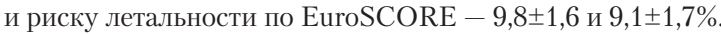

Концентрацию NT-proBNP определяли перед оперативным вмешательство на иммунохимическом экспресс-анализаторе Cardiac reader (Roche Diagnostics) с использованием стандартных тест-наборов.

Всех больных оперировали в условиях многокомпонентной общей анестезии, обеспечиваемой различными комбинациями фентанила, мидазолама, пропофола, севофлурана и рокурония. ИК проводили аппаратами ИК Stockert c мембранными оксигенаторами в нормотермическом режиме.
Во время пережатия аорты миокард защищали методом кровяной фармакологической кардиоплегии.

Мониторинг центральной гемодинамики (ЦГД) осуществляли с помощью системы Viridia (Hewlett Packard). Для изучения насосной функции сердца и кровообращения в малом круге использовали катетеры Swan-Ganz, сердечный выброс измеряли методом болюсной холодовой термодилюции. Регистрировали систолическое, диастолическое и среднее артериальное давление (АД, АД, АД $_{\mathrm{cp}}$ ) инвазивно, частоту сердечных сокращений (ЧСС), давление в правом предсердии (ДПП), систолическое, диастолическое и среднее давление в легочной артерии (ДЛА ление в легочной артерии (ЗДЛА). По стандартным формулам рассчитывали сердечный индекс (СИ), индексы ударного объема (ИУО), общего периферического сосудистого сопротивления (ИОПСС), общего легочного сосудистого сопротивления, ударной работы левого (ИУРЛЖ) и правого (ИУРПЖ) желудочков. Вычисляли насосные коэффициенты (НК) левого и правого желудочков (НКЛЖ, НКПЖ) по формулам: НКЛЖ = ИУРЛЖ/ЗДЛА; НКПЖ = ИУРПЖ/ДПП. Для расчета коронарных перфузионных градиентов (КПГ) использовали формулы: КПГ 1 = АД д - ЗДЛА; КПГ $2=$ АД $_{д}-$ ДПП; КПГ ${ }_{3}=$ АД $_{c}$

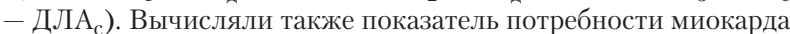
в кислороде $\left(\mathrm{RPP}=\mathrm{A}_{\text {дс }} \cdot\right.$ ЧCC) и мощность сердца $\left(\right.$ ИМС $=$ СИ $•$ АД $\left.{ }_{\text {ср }} / 451\right)[10]$. Показатели ЦГД обрабатывали на этапах: I - после кожного разреза, II - конец операции. Анализировали данные дооперационного клинико-инструментального обследования, назначение симпатомиметических кардиотоников и вазопрессоров, использование внутриаортальной баллонной контрпульсации (ВАБК), раннюю послеоперационную летальность, длительность ИВЛ и нахождения больных в отделении интенсивной терапии (ОИТ).

Статистический анализ выполнили с помощью компьютерной программы Excel с опцией «Анализ данных». Вычисляли средние арифметические значения $(M)$, ошибки средних величин $(m)$, коэффициенты парной линейной корреляции $(r)$. Предикторную значимость показателей определяли с помощью регрессионного анализа по значениям вероятности влияния $(p)$. При анализе статистической значимости использовали $t$-критерий Стьюдента. Различия значений, достоверность корреляционных связей и предикторное влияние считали значимыми при уровне вероятности более $95 \%(p<0,05)$.

\section{Результаты и обсуждение}

Креатининемия в 1-й группе составляла 96-117 (103 $\pm 3,3)$, во 2-й $-137-262(183 \pm 12,9)$ мкмоль $/$ л $(p<0,05)$; NT-proBNP - 1000-2300 (1397 \pm 139$)$ и $1171-2627$ $(1908 \pm 170)$ пг/мл $(p<0,05)$.

В предперфузионный период большинство показателей, характеризующих ЦГд и насосную функцию сердца (табл. 1, этап I), у обследованных больных не имели межгрупповых отличий. В 1-й группе были меньше, чем во 2-й, значения АД После ИК (этап II) межгрупповые отличия отсутствовали. Можно отметить лишь тенденцию $(p<0,1)$ к более высокому уровню ДЛАд у больных 2-й группы.

Поэтапная динамика показателей в группах отличалась существенно. У больных 1-й группы увеличение СИ и ИМС (на 56\%) после ИК обеспечивалось приростом ЧСС. ИУО и другие показатели насосной функции 
Таблица 1

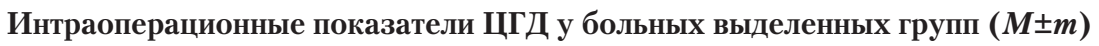

\begin{tabular}{|c|c|c|c|}
\hline \multirow[t]{2}{*}{ Показатель } & \multirow[t]{2}{*}{ Группа } & \multicolumn{2}{|c|}{ Значения показателей на этапах исследования } \\
\hline & & I & II \\
\hline \multirow{2}{*}{ АД, мм рт. ст. } & $1-9$ & $100,1 \pm 3,1$ & $108,0 \pm 4,2$ \\
\hline & $2-я$ & $116,7 \pm 4,2^{*}$ & $113,0 \pm 3,3$ \\
\hline \multirow[t]{2}{*}{ АД, мм рт. ст. } & $1-я$ & $58,6 \pm 2,2$ & $56,6 \pm 4,2$ \\
\hline & $2-9$ & $64,0 \pm 3,5$ & $63 \pm 3$ \\
\hline \multirow[t]{2}{*}{ АД ${ }_{c p}$, мм рт. ст. } & $1-я$ & $72,4 \pm 2,1$ & $73,7 \pm 3,4$ \\
\hline & $2-я$ & $81,5 \pm 2,0^{*}$ & $80,0 \pm 2,9$ \\
\hline \multirow[t]{2}{*}{ ЧСС, мин ${ }^{-1}$} & $1-я$ & $66,7 \pm 4,0$ & $79,2 \pm 3,6^{\#}$ \\
\hline & $2-я$ & $76,2 \pm 4,1$ & $86,5 \pm 6,3$ \\
\hline \multirow[t]{2}{*}{ ДПП, мм рт. ст. } & $1-я$ & $8,7 \pm 1,3$ & $7,9 \pm 0,4$ \\
\hline & $2-я$ & $8,0 \pm 1,1$ & $7,4 \pm 0,9$ \\
\hline \multirow{2}{*}{ ДЛА, мм рт. ст. } & $1-9$ & $33,8 \pm 5,7$ & $27,4 \pm 2,6$ \\
\hline & $2-я$ & $43,1 \pm 8,2$ & $33,4 \pm 3,9$ \\
\hline \multirow[t]{2}{*}{ ДЛА ${ }_{д}$, мм рт. ст. } & $1-я$ & $18,9 \pm 3,6$ & $15,4 \pm 1,3$ \\
\hline & $2-я$ & $22,6 \pm 4,1$ & $19,6 \pm 1,7$ \\
\hline \multirow{2}{*}{ ДЛА ${ }_{\text {ср }}$, мм рт. ст. } & $1-я$ & $23,9 \pm 4,4$ & $19,4 \pm 1,7$ \\
\hline & $2-я$ & $29,4 \pm 5,4$ & $24,2 \pm 2,4$ \\
\hline \multirow[t]{2}{*}{ ЗДЛА, мм рт. ст. } & $1-я$ & $14,0 \pm 2,8$ & $11,8 \pm 1,2$ \\
\hline & $2-я$ & $17,6 \pm 2,9$ & $13,0 \pm 1,5$ \\
\hline \multirow[t]{2}{*}{ СИ, л/мин • $\mathrm{M}^{2}$} & $1-9$ & $2,02 \pm 0,1$ & $2,96 \pm 0,2^{\#}$ \\
\hline & $2-я$ & $1,98 \pm 0,1$ & $3,34 \pm 0,3^{\#}$ \\
\hline \multirow{2}{*}{ ИУО, мл/м² } & $1-я$ & $30,5 \pm 1,9$ & $39,0 \pm 4,5$ \\
\hline & $2-9$ & $27,5 \pm 3,1$ & $38,6 \pm 4,5^{\#}$ \\
\hline \multirow[t]{2}{*}{ ИОПСС, дин $\bullet c^{\bullet} \mathrm{M}^{2} / \mathrm{cm}^{5}$} & $1-я$ & $2247 \pm 191$ & $2502 \pm 198$ \\
\hline & $2-я$ & $3130 \pm 359 *$ & $2561 \pm 216$ \\
\hline \multirow[t]{2}{*}{ ИОЛСС, дин • $\bullet \mathrm{M}^{2} / \mathrm{cm}^{5}$} & $1-9$ & $436,3 \pm 81,0$ & $222,0 \pm 32,2$ \\
\hline & $2-я$ & $586,7 \pm 222,0$ & $315 \pm 65$ \\
\hline \multirow[t]{2}{*}{ ИУРЛЖ, гм/м² } & $1-я$ & $23,9 \pm 2,8$ & $33,9 \pm 4,6$ \\
\hline & $2-я$ & $24,5 \pm 3$ & $35,2 \pm 4,6$ \\
\hline \multirow[t]{2}{*}{ ИУРПЖ, гм/м² } & $1-я$ & $6,2 \pm 1,8$ & $6,4 \pm 1,0$ \\
\hline & $2-я$ & $7,0 \pm 1,4$ & $8,01 \pm 0,9$ \\
\hline \multirow[t]{2}{*}{ НКЛЖ, гм/м²/мм рт. ст. } & $1-я$ & $2,1 \pm 0,4$ & $3,4 \pm 0,8$ \\
\hline & $2-я$ & $1,7 \pm 0,2$ & $3,5 \pm 0,7^{\#}$ \\
\hline \multirow[t]{2}{*}{ НКПЖ, гм/м²/мм рт. ст. } & $1-9$ & $0,9 \pm 0,3$ & $0,8 \pm 0,1$ \\
\hline & $2-я$ & $0,76 \pm 0,08$ & $1,2 \pm 0,2^{\#}$ \\
\hline \multirow[t]{2}{*}{ КПГ $\Gamma_{1}$, мм рт. ст. } & 1-я & $44,4 \pm 4,6$ & $43,3 \pm 4,2$ \\
\hline & $2-я$ & $48,6 \pm 2,3$ & $50,4 \pm 3,8$ \\
\hline \multirow{2}{*}{ КП $\Gamma_{2}$, мм рт. ст. } & $1-9$ & $49,1 \pm 3,1$ & $47,1 \pm 4,4$ \\
\hline & 2-я & $57,2 \pm 2,3$ & $55,5 \pm 3,3$ \\
\hline \multirow[t]{2}{*}{ КПГ } & $1-я$ & $66,2 \pm 7,9$ & $81,4 \pm 4,4$ \\
\hline & $2-я$ & $71,1 \pm 9,7$ & $78,3 \pm 5,9$ \\
\hline \multirow[t]{2}{*}{ RPP, мм рт. ст. $\bullet$ мин $^{-1}$} & $1-9$ & $6626 \pm 442$ & $8607 \pm 650^{\#}$ \\
\hline & $2-я$ & $8580 \pm 785$ & $9897 \pm 811$ \\
\hline ИМС, вт $/ \mathrm{M}^{2}$ & $1-я$ & $0,32 \pm 0,02$ & $0,5 \pm 0,05^{\#}$ \\
\hline & 2-я & $0,37 \pm 0,03$ & $0,6 \pm 0,06^{\#}$ \\
\hline
\end{tabular}

Примечание. * - достоверность $(p<0,05)$ межгрупповых отличий; ${ }^{*}-$ достоверность $(p<0,05)$ поэтапных отличий.

сердца не изменялись. На фоне неизменных КПГ (условия для коронарного кровотока) увеличивался показатель потребности миокарда в кислороде (RPP). У больных 2-й группы после ИК увеличение СИ и ИМС (на $62 \%$ ) происходило в основном за счет ИУО. При этом возрастали НКлЖ и НКПЖ, характеризуя улучшение насосной функции сердца. RPP и КПГ не изменялись, что указывает на отсутствие значимых изменений в детерминантах кислородного баланса миокарда.

Интенсивность симпатомиметической терапии в постперфузионный период (табл. 2) у больных выделенных групп была практически одинаковой, также не различались частота использования ВАБК, длительность послеоперационной ИВЛ и пребывания в ОИТ у выживших больных. Не было отличий и в госпитальной летальности, которая в обеих группах оказалась существенно выше прогнозируемой летальности по шкале EuroSCORE.

Регрессионный анализ показал (табл. 3), что по всей выборке оперированных больных уровень NTproBNP оказался более значимым предиктором госпитальной летальности, чем показатель, рассчитанный по шкале EuroSCORE. Аналогичная закономерность была характерна для больных без гиперкреатининемии, у которых и NT-proBNP, и шкала EuroSCORE имели отчетливую предикторную значимость. Корреляционный анализ выявил лишь тенденцию к связи между NTproBNP и прогнозируемой летальностью по всей выборке (рис. 1). У больных без гиперкреатининемии корреляция была выраженной (рис. 2). 
Симпатомиметическая терапия и показатели раннего послеоперационного периода у больных выделенных групп $(M \pm m)$

\begin{tabular}{lcc}
\hline Показатель & \multicolumn{2}{c}{ Значения показателей в группах } \\
\cline { 2 - 3 } & $\mathbf{1 - я}$ & 2-я \\
\hline Расход допамина, мкг/кг/мин & $5 \pm 0,5$ & $5,3 \pm 0,6$ \\
Расход адреналина и/или норадреналина, нг/кг/мин & $147 \pm 54,6$ & $130 \pm 40,7$ \\
Использование ВАБК, \% & $18,2 \pm 11,6$ & $10 \pm 9,5$ \\
Длительность ИВЛ, ч & $15 \pm 1,5$ & $18,7 \pm 2,3$ \\
Госпитализация в ОИТ у выживших больных, сут & $1,8 \pm 0,5$ & $2,0 \pm 0,7$ \\
Госпитальная летальность, \% & $27,3 \pm 13,4$ & $20,0 \pm 12,6$ \\
\hline
\end{tabular}

Предикторная значимость предоперационного уровня NT-proBNP

Таблища 3 и расчетной летальности по шкале EuroSCORE у обследованных больных

\begin{tabular}{lcc}
\hline Группа больных & Предикторы госпитальной летальности & EuroSCORE \\
\cline { 2 - 3 } & NT-proBNP & $p=0,04(r=0,44)$ \\
Все обследованные & $p=0,012(r=0,54)$ & $p=0,026(r=0,66)$ \\
С нормокреатининемией & $p=0,012(r=0,72)$ & $p=0,61(r=0,18)$ \\
С гиперкреатининемией & $p=0,06(r=0,6)$ & $p 18$ \\
\hline
\end{tabular}

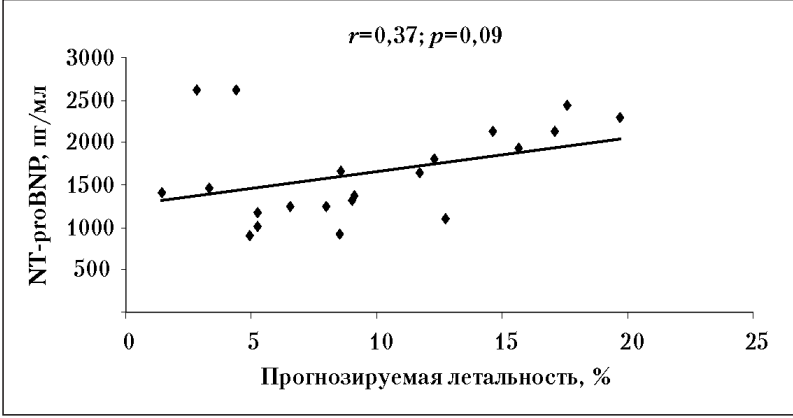

Рис. 1. Тенденция к взаимосвязи между дооперационным уровнем NT-proBNP и прогнозируемой летальностью по шкале EuroSCORE по всем обследованным больным.

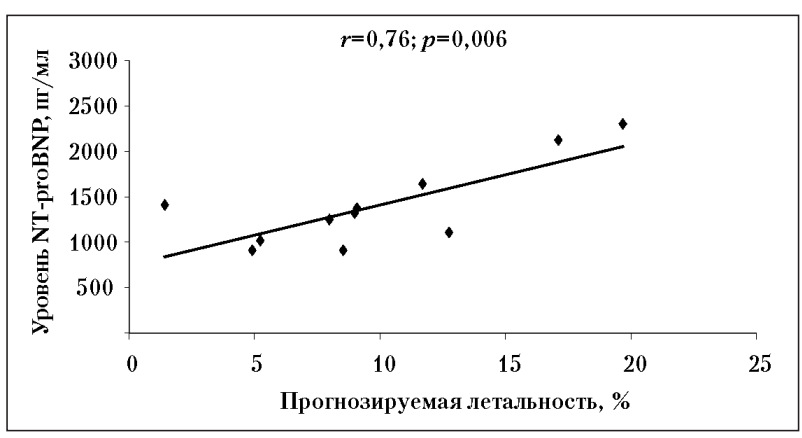

Рис. 2. Взаимосвязь между дооперационным уровнем NTproBNP и прогнозируемой летальностью по шкале EuroScore у больных 1-й группы.

У больных с гиперкреатининемией показатель «предполагаемая летальность по EuroSCORE» полностью потерял значимость в прогнозе реальной летальности. Уровень NT-proBNP в этой же группе проявлял отчетливую тенденцию $(p<0,1)$ к предикторному влиянию. Корреляция между изучаемыми показателями отсутствовала (рис. 3).

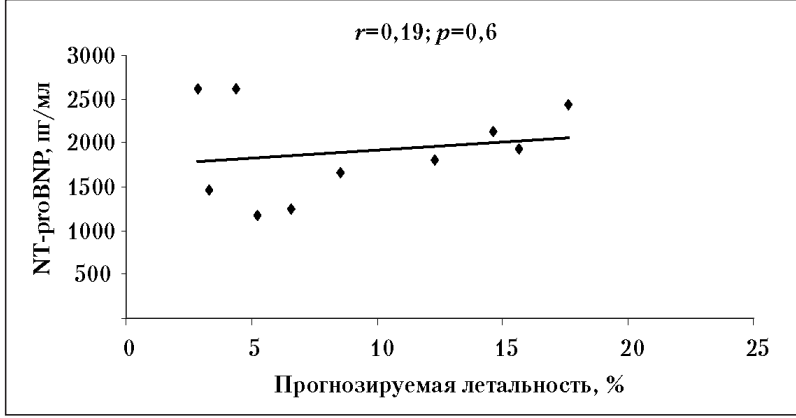

Рис. 3. Отсутствие взаимосвязи между дооперационным уровнем NT-proBNP и прогнозируемой летальностью по шкале EuroSCORE у больных 2-й группы.

Обсуждая результаты исследования, прежде всего отметим, что указания на возможность резкого повышения уровня NT-proBNP (1000 пг/мл и более) у кардиохирургических больных относительно немногочисленны. В большинстве работ исследователи приводят данные о высоком риске осложнений у этой категории больных при значениях биомаркера выше 600-650 пг/мл [11, 12], реже - выше 900 пг/ мл [11]. При реваскуляризации миокарда у больных со значимым снижением сократительной функции сердца (ФИЛЖ менее 35\%) выявили рез-

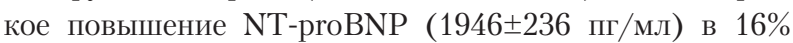
наблюдений [4]. Авторы указали, что содержание биомаркера выше 1200 пг/мл указывает на высокий операционный риск, а уровень 2000 пг/мл и выше свидетельствует о крайне высоком риске периоперационной сердечной недостаточности [4].

Не вызывает сомнений, что повышение уровня NT-proBNP в крови может вызываться нарушением функции почек $[5,8]$. Вместе с тем, когда у конкретного больного выявлены резкое повышение содержания биомаркера и гиперкреатининемия, оценка риска опера- 
ции с ИК затрудняется, поскольку остается неясным вклад избыточной секреции и нарушения экскреции NT-proBNP. Обследованные нами группы больных не различались по тяжести исходного состояния и ФИЛЖ, однако содержание биомаркера у больных с гиперкреатининемией (2-я группа) было в 1,4 раза выше. Тем не менее интраоперационная ЦГД и изученные клинические показатели не имели межгрупповых отличий. Клиническое течение периоперационного периода у больных 2-й группы было не тяжелее, чем в 1-й.

Отметили, что состояние ЦГД после ИК было более благоприятным у больных 2-й группы, что проявлялось увеличением сердечного выброса за счет ИУО с соответствующим увеличением НКЛЖ и НКПЖ. Такая гемодинамическая реакция вполне стандартна для операций реваскуляризации миокарда [3] и может рассматриваться как условная «норма» для раннего постперфузионного периода. Прирост СИ за счет ЧСС, отмеченный в 1-й группе, напротив, может указывать на истощение объемных механизмов регуляции насосной функции сердца, а также приводить к дисбалансу миокардиальных потребления и доставки кислорода. Однако патофизиологические особенности поддержания сердечного выброса у обследованных больных не реализовались в клинически значимые межгрупповые отличия и не оказали влияния на госпитальную летальность.

Таким образом, совокупность полученных результатов дает все основания считать, что резко повышенный уровень NT-proBNP не теряет своей предикторной значимости у кардиохирургических больных с гиперкреатининемией. Значения NT-proBNP выше 1000 пг/мл на фоне гиперкреатининемии до 260 мкмоль/л следует рассматривать как показатель максимально высокого операционного риска. Ограниченное число наблюдений в настоящем исследовании не позволяет установить точные количественные соотношения степени гиперкреатинемии и повышения биомаркера у рассматриваемой категории больных. Однако при уровне NT-proBNP выше 1000 пг/мл, вероятно, «поправка на гиперкреатининемию», рекомендуемая отдельными клиницистами [6], будет не велика, а сам биомаркер сохранит свою предикторную значимость [8, 9].

Как показали настоящие результаты и другие исследования [4], шкала EuroSCORE, сохраняя в целом свою роль «инструмента» для оценки операционного риска реваскуляризации миокарда, у больных с выраженным повышением уровня NT-proBNP может давать заметные погрешности, как завышая, так и занижая предполагаемую летальность [4]. Данные о взаимосвязи содержания биомаркера в крови и рассчитанной по EuroSCORE летальности неоднородны. При существенном снижении ФИЛж

\section{Литература}

1. Козлов И. А., Кричевский Л. А., Шумаков Д. В. и соавт. Плазменный уровень неактивной части предшественника В-типа натрийуретического пептида как предиктор функции сердца при операциях с искусственным кровообращением. Анестезиология и реаниматология 2006; 3: 30-33.

2. Козлов И. А., Харламова И. Е. Натрийуретические пептиды: биохимия, физиология, клиническое использование. Общая реаниматология 2009: V (1): 89-97. между этими показателями возможна умеренная корреляционная связь [4]. Однако у больных, обследованных в рамках настоящего исследования, такая связь имела лишь характер тенденции (см. рис. 1). Это было обусловлено полным нарушением корреляции между уровнем NTproBNP и показателем EuroSCORE при гиперкреатининемии (см. рис. 2). Отмеченное явление представляется неожиданным, поскольку в шкалу EuroSCORE включена гиперкреатининемия [7]. Значимость повышения содержания креатинина в крови как самостоятельного предиктора ранних послеоперационных осложнений и госпитальной летальности в настоящее время не вызывает сомнений $[7,13]$. Однако в шкале EuroSCORE оценка этого фактора риска имеет пороговый характер, что может снижать чувствительность системы оценки у больных с разными степенями гиперкреатининемии. Фактором уменышения прогностической значимости шкалы EuroSCORE, вероятно, является сочетание гиперкреатининемии и резко повышенного уровня NT-proBNP (см. выше).

Анализируя информативность одновременного повышения содержания в крови NT-proBNP и креатинина, следует отметить, что некоторые авторы предпринимают попытки повысить специфичность и чувствительность лабораторного маркера функции сердца путем одновременного определения его концентрации в крови и в моче [6]. Разработаны методы измерения уровня NT-proBNP в моче [14]. Некоторые исследователи предпринимали попытки использовать содержание пептида в моче как альтернативу концентрации в крови при оценки тяжести хронической недостаточности кровообращения [15,16]. Можно предположить, что в рассматриваемой клинической ситуации максимально информативным прогностическим критерием окажется показатель, включающий в себя уровень NT-proBNP в крови и клиренс пептида. Однако таких исследований у кардиохирургических больных с высоким операционным риском до настоящего времени не выполняли. Резюмируя настоящие исследования, можно подчеркнуть высокую информативность определения NT-proBNP у больных, оперируемых с ИК, включая наиболее сложные в диагностическом аспекте клинические наблюдения.

\section{Заключение}

Полученные результаты позволяют сделать вывод, что содержание NT-proBNP в крови 1000 пг/мл и выше сохраняет свою значимость, как фактор высокого операционного риска, при реваскуляризации миокарда в условиях ИК у больных с гиперкреатининемией в пределах 140-270 мкмоль/л.

3. Козлов И. А., Харламова И. Е. Повышенный уровень натрийуретического пептида B-типа(NT-proBNP) как фактор риска у кардиохирургических больных. Общая реаниматология 2010; VI (1): 49-55.

4. Мороз В. В., Никифоров Ю. В., Кричевский Л. А. и соавт. Значение сердечного пептида NT-proBNP в оценке риска реваскуляризации миокарда у больных со сниженной фракцией изгнания левого желудочка. Общая реаниматология 2010; VI (2): 38-42.

5. Vanderheyden M., Bartunek J., Goethals M. Brain and other natriuretic peptides: molecular aspects. Eur. J. Heart Fail. 2004; 6 (3) $261-268$. 
6. Linssen G. C., Damman K., Hillege H. L. et al. Urinary N-terminal prohormone brain natriuretic peptide excretion in patients with chronic heart failure. Circulation 2009; 120 (1): 35-41.

7. Mosorin M. A., Heikkinen J.J., Pokela M. et al. Immediate and 5-year outcome after coronary artery bypass surgery in very high risk patients (additive EuroSCORE $\geqslant 10$ ). J. Cardiovasc. Surg. (Torino) 2011; 52 (2): 271-276.

8. Bernstein L. H., Zions M. Y., Haq S. A. et al. Effect of renal function loss on NT-proBNP level variations. Clin. Biochem. 2009; 42 (10-11): 1091-1098.

9. Srisawasdi P., Vanavanan S., Charoenpanichkit C., Kroll M. H. The effect of renal dysfunction on BNP, NT-proBNP, and their ratio. Am. J. Clin Pathol. 2010; 133 (1): 14-23.

10. Fincke R., Hochman J. S., Lowe A. M. et al. Cardiac power is the strongest hemodynamic correlate of mortality in cardiogenic shock: A report from the SHOCK trial registry. J. Am. Coll. Cardiol. 2004 44 (2): $340-348$
11. Reyes G., Forés G., Rodríguez-Abella R. H. et al. NT-proBNP in cardiac surgery: a new tool for the management of our patients? Interact. Cardiovasc. Thorac. Surg. 2005; 4 (3): 242-247.

12. Weber M., Hamm C. Role of B-type natriuretic peptide (BNP) and NTproBNP in clinical routine. Heart 2006; 92 (6): 843-849.

13. Barbosa R. R., Cestari P. F, CapelettiJ. T. et al. Impact of renal failure on in-hospital outcomes after coronary artery bypass surgery. Arq. Bras. Cardiol. 2011; 97 (3): 249-253.

14. Palmer S. C., Endre Z. H., Richards A. M., Yandle T. G. Characterization of NT-proBNP in human urine. Clin. Chem. 2009; 55 (6): 1126-1134.

15. Michielsen E. C., Bakker J. A., Kimmenade R. R. et al. The diagnostic value of serum and urinary NT-proBNP for heart failure. Ann. Clin. Biochem. 2008; 45 (Pt 4): 389-394.

16. Ng L. L., Geeranavar S., Jennings S. C. et al. Diagnosis of heart failure using urinary natriuretic peptides. Clin. Sci. (Lond. ) 2004; 106 (2): 129-133.

Поступила 05.09.11

\section{ОБЩАЯ РЕАНИМАТОЛОГИЯ}

Научно-практический журнал «Общая реаниматология», входящий в перечень ВАК РФ, предназначен для врачей анестезиологов-реаниматологов и научных сотрудников.

Тематика журнала: патогенез, клиника, диагностика, лечение, профилактика и патологическая анатомия критических, терминальных и постреанимационных состояний. Вопросы оказания догоспитальной помощи при критических состояниях. Вопросы обучения населения и медицинского персонала приемам оказания неотложной помощи при критических состояниях.

Аудитория: лечебные учреждения; высшие учебные заведения медицинского профиля; медицинские учреждения последипломного образования, Федеральные и региональные органы управления здравоохранением, медицинские научно-исследовательские институты; медицинские библиотеки.

\section{П О Д П И С К А}

В любом почтовом отделении связи по каталогу «Роспечать»

• индекс 46338 - для индивидуальных подписчиков

• индекс 46339 - для предприятий и организаций

Диссертации на соискание ученой степени доктора наук без опубликования основных научных результатов в ведущих журналах и изданиях, перечень которых утвержден Высшей аттестационной комиссией, будут отклонены в связи с нарушением п. 11 Положения о порядке присуждения ученых степеней.

Перечень журналов ВАК, издаваемых в Российской Федерации по специальности 14.01.20 «Анестезиология и реаниматология», в которых рекомендуется публикация основных результатов диссертаций на соискание ученой степени доктора и кандидата медицинских наук:

- Анестезиология и реаниматология;

- Общая реаниматология. 